\title{
Salmeterol in paediatric asthma
}

\author{
Catherine Byrnes, Stephen Shrewsbury, Peter J Barnes, Andrew Bush
}

\begin{abstract}
Background-The addition of long acting inhaled $\beta_{2}$ agonists is recommended at step 3 of the British guidelines on asthma management but a recent study suggested no additional benefit in children with asthma.

Methods-The aim of this study was to compare, in a double blind, three way, crossover study, the effects of the addition of salmeterol $50 \mu \mathrm{g}$ bd, salmeterol $100 \mu \mathrm{g}$ bd, and salbutamol $200 \mu \mathrm{g}$ qds in asthmatic children who were symptomatic despite treatment with inhaled corticosteroids in a dose of at least $400 \mu \mathrm{g} /$ day over a one month period. Symptom scores, morning and evening peak expiratory flow (PEF) rates, use of rescue medication, spirometric indices, and histamine challenge were measured.
\end{abstract}

Results-Forty five children aged 5-14 years were enrolled. All three treatments improved asthma control, morning and evening PEF rates, and spirometric indices with no change in bronchial hyperreactivity. Mean morning PEF was significantly better during the salmeterol treatment periods than with salbutamol treatment $(p<0.05)$. The analysis of mean morning PEF gave an estimated treatment difference of $9.6 \mathrm{1} / \mathrm{min}$ for salmeterol $50 \mu \mathrm{g}$ bd versus salbutamol $200 \mu \mathrm{g}$ qds (95\% confidence interval (CI) 2.1 to 17.1 ), and an estimated treatment difference of $13.8 \mathrm{l} / \mathrm{min}$ for salmeterol $100 \mu \mathrm{g}$ bd versus salbutamol $200 \mu \mathrm{g}$ qds (95\% CI 6.0 to 21.5 ). There were no significant differences between the two doses of salmeterol and all treatments were well tolerated.

Conclusions-In this population of moderate to severe asthmatic children on inhaled corticosteroids, salmeterol in a dose of either $50 \mu \mathrm{g}$ bd or $100 \mu \mathrm{g}$ bd is significantly more effective at increasing the morning PEF rate over a one month period than salbutamol $200 \mu \mathrm{g}$ qds. The data provided no significant evidence of a difference in efficacy between the two doses of salmeterol, $50 \mu \mathrm{g}$ and $100 \mu \mathrm{g}$. A trial of salmeterol $100 \mu \mathrm{g}$ bd may be worth considering in those still symptomatic on the lower dose.

(Thorax 2000;55:780-784)

Keywords: asthma; children; salmeterol; salbutamol; long acting $\beta$ agonists

Asthma is characterised by variable airflow obstruction related to bronchial hyperreactivity to a variety of stimuli owing to underlying airway inflammation. Guidelines for asthma treatment in children ${ }^{1}$ recommend the early introduction of inhaled corticosteroids to treat airway inflammation. If a child fails to respond to the equivalent of $800 \mu \mathrm{g} /$ day of beclomethasone (step 2 of the British guidelines), then either the dose of inhaled corticosteroids may be increased or a long acting inhaled $\beta_{2}$ agonist added to the regime. Studies in mixed populations of adult and paediatric asthmatic subjects have shown that the addition of salmeterol ${ }^{23}$ or formoterol ${ }^{4}$ results in better lung function and control of exacerbations than doubling the dose of inhaled corticosteroids, thereby apparently establishing an important role for long acting $\beta_{2}$ agonists at step 3. Studies in children have given conflicting results. Russell et a $\bar{P}$ showed improvement in morning and evening peak flow rate, recorded symptoms, and bronchodilator use when salmeterol was added to inhaled steroids. However, a more recent paediatric study showed no benefit from either doubling the dose of inhaled steroids or adding inhaled salmeterol in children with asthma, ${ }^{6}$ which suggests that long acting $\beta_{2}$ agonists have a lesser role in children than in adults. We designed this study to compare the effects of salmeterol $50 \mu \mathrm{g} \mathrm{bd}$, salmeterol $100 \mu \mathrm{g}$ bd, and salbutamol $200 \mu \mathrm{g}$ qds in children with inadequately controlled asthma despite treatment with $\geqslant 400 \mu \mathrm{g} /$ day inhaled beclomethasone or equivalent.

\section{Methods}

PATIENTS

Children were eligible to enter the study if at the screening visit they were aged 5-16 years and required $\geqslant 400 \mu \mathrm{g} /$ day inhaled beclomethasone or equivalent, and showed evidence of reversible airflow obstruction-namely, a $15 \%$ increase in peak expiratory flow (PEF) or forced expiratory volume in one second $\left(\mathrm{FEV}_{1}\right)$ after inhaling $400 \mu \mathrm{g}$ salbutamol from a Diskhaler, short acting bronchodilators having been withheld for more than four hours. Exclusion criteria were admission to hospital for any reason, treatment with oral corticosteroids or change in regular asthma treatment during the four weeks before starting the study, serious concomitant disease, and an acute respiratory infection requiring new prescribed treatment during the four weeks before starting the study. Treatment with oral $\beta$ agonists, theophylline, or inhaled anticholinergic agents was not permitted.

\section{STUDY DESIGN}

This was a double blind, double dummy, three way, crossover study with a run in and three treatment periods. During the run in period the children took their regular inhaled corticosteroids and were asked to use inhaled salbutamol from a Diskhaler for relief of symptoms. In
June 2000

Accepted for publication

14 June 2000 
order to be eligible for the treatment periods, at the end of the two week run in period (see below) they were required to have either (1) an $\mathrm{FEV}_{1}<80 \%$ predicted four hours after last inhaling a short acting $\beta_{2}$ agonist or (2) a mean morning PEF over the last seven days of the run in period of $<80 \%$ of the predicted normal or (3) a diurnal variation in PEF of at least $20 \%$ on at least four of the last seven days of the run in period where diurnal variation was defined as:

$\left.\left[\mathrm{PEF}_{\text {previous evening }}-\mathrm{PEF}_{\text {following morning }}\right] /\left[\mathrm{PEF}_{\text {previous evening }}\right] \%\right)$.

The treatment periods were a double blind comparison of salmeterol $50 \mu \mathrm{g}$ bd with salmeterol $100 \mu \mathrm{g}$ bd and salbutamol $200 \mu \mathrm{g}$ qds for four weeks each. Treatment order was randomised by a computer generated random code. Between six and nine subjects were randomised to each of the six possible treatment sequences. Each child inhaled from three Diskhalers regularly during each of the three study periods to ensure blinding. In addition, active salbutamol $200 \mu \mathrm{g} /$ dose could be used up to six times a day from a Diskhaler for relief of symptoms. Adherence to treatment was assessed by counting the number of blisters returned. There was no washout between treatment periods. At the end of the study there was a final two week period of monitoring during which the child used only inhaled salbutamol as required.

Based on a residual standard deviation of $35 \mathrm{l} / \mathrm{min}$, 54 evaluable patients would give a power of at least $80 \%$ to detect a treatment difference in mean morning PEF of $131 / \mathrm{min}$ between any two treatments at a 5\% significance level. It was therefore planned that approximately 72 boys and girls would be recruited with the aim of providing 54 evaluable subjects.

\section{MEASUREMENTS}

There were a total of six visits (start of study, end of run in period, end of each treatment period, end of two week post-study period). At each visit the child was assessed, record cards (below) were examined, and medication was returned as appropriate. The investigator and the child or guardian assessed the effectiveness of treatment independently but subjectively. Spirometric tests were performed at each visit using a Compact Vitalograph (Hamburg, Germany) which was calibrated before each set of measurements with a one litre syringe. The best of three reproducible measurements of $\mathrm{FEV}_{1}$ was recorded. PEF was measured separately using a Wright peak flow meter (London, UK). Histamine challenge was performed in a subgroup of children (below). The baseline results are shown in table 1.

Children were asked to keep a diary card throughout the study. They were asked to record daytime and night time symptoms and use of rescue medication. They were provided with a Wright mini-peak flow meter and asked to record the best of three peak flows in the morning and in the evening before taking their study medication. Only the last two weeks of
Table 1 Mean (SD) baseline lung function results

\begin{tabular}{llc}
\hline Baseline measure & $n$ & Mean (SD) \\
\hline Mean morning PEF (1/min) & 43 & $249(69)$ \\
Morning PEF (\% predicted) & 43 & $94(19)$ \\
Mean evening PEF (1/min) & 43 & $255(43)$ \\
Evening PEF (\% predicted) & 43 & $96(19)$ \\
FEV $_{1}(1)$ & 44 & $1.60(0.50)$ \\
PC $_{20}(\mathrm{mg} / \mathrm{ml})$ & 21 & $0.28(1.94)^{\star}$
\end{tabular}

$\mathrm{PEF}=$ peak expiratory flow; $\mathrm{FEV}_{1}=$ forced expiratory volume in one second; $\mathrm{PC}_{20}=$ concentration of histamine provoking a fall in $\mathrm{FEV}_{1}$ of $20 \%$.

${ }^{\star}$ Geometric mean and coefficient of variation.

the diary card data were used in the final analysis.

BRONCHIAL HYPERREACTIVITY

Bronchial challenge was performed in children who had an $\mathrm{FEV}_{1}$ of more than $75 \%$ predicted and an absolute value of more than one litre at the end of each of the three study periods. Study medications were omitted on the morning of the challenge. Test medications were given in a Wright nebuliser, airflow $8 \mathrm{l} / \mathrm{min}$ from an air cylinder, with the child breathing tidally and wearing a noseclip. Nebulisation time was two minutes at each dose, with $\mathrm{FEV}_{1}$ and PEF measured at the end of nebulisation. Normal saline was inhaled first, followed by histamine acid phosphate in doubling doses from 0.03 to $32 \mathrm{mg} / \mathrm{ml}$. The test was halted when $\mathrm{FEV}_{1}$ had fallen by $\geqslant 20 \%$ and the concentration of histamine producing a $20 \%$ fall in $\mathrm{FEV}_{1}\left(\mathrm{PC}_{20}\right)$ was determined by linear interpolation.

\section{STATISTICAL METHODS}

Only patients with at least one day's data during weeks 3 or 4 in at least two periods and at least one day's data during the last week of the run in period were included in the efficacy analyses. The primary efficacy end point was the mean morning PEF. An analysis of covariance, appropriate for a three way crossover, ${ }^{7}$ was used to analyse these data. The covariates used were subject, randomisation treatment sequence, period effects, treatment effects, and period $\times$ treatment interaction. The carryover effect was tested but was not found to be significant $(p=0.62)$. The period and period $x$ treatment interaction effects were also found not to explain significantly the variation in the data. However, these terms were left in the model as they were included in the planned analysis.

Secondary end points - mean evening PEF, percentage predicted morning and evening PEF $(-425.5714+5.2428 \times$ height $)$, and the log transformed histamine $\mathrm{PC}_{20}$-were also analysed using the described method of analysis of covariance. The median number of blisters of day and night rescue salbutamol were analysed using the Wilcoxon rank sum test via Koch's method ${ }^{8}$ which performs pairwise treatment comparisons whilst adjusting for period effects. The day and night symptom scores and the patient's and physician's assessments were also analysed using this method.

Pairwise comparisons of the most common adverse events were tested using Prescott's test. 
Table 2 Comparison of lung function results for the three treatments over a four week period

\begin{tabular}{|c|c|c|c|c|c|}
\hline Treatment & $n$ & $\begin{array}{l}\text { Adjusted } \\
\text { mean }\end{array}$ & $\begin{array}{l}\text { Estimated treatment } \\
\text { difference versus } \\
\text { salbutamol } 200 \mu \mathrm{g}\end{array}$ & $95 \% C I$ & $p$ value \\
\hline \multicolumn{6}{|c|}{ Mean morning PEF (l/min) } \\
\hline Salmeterol $50 \mu \mathrm{g}$ & 40 & 262.0 & 9.6 & 2.1 to 17.1 & 0.013 \\
\hline Salmeterol $100 \mu \mathrm{g}$ & 38 & 266.2 & 13.8 & 6.0 to 21.5 & 0.001 \\
\hline Salbutamol $200 \mu \mathrm{g}$ & 40 & 252.4 & & & \\
\hline \multicolumn{6}{|c|}{ Predicted morning PEF (\%) } \\
\hline Salmeterol $50 \mu \mathrm{g}$ & 40 & 98.7 & 3.6 & 0.4 to 6.7 & 0.028 \\
\hline Salmeterol $100 \mu \mathrm{g}$ & 38 & 99.4 & 5.4 & 2.1 to 8.6 & 0.002 \\
\hline Salbutamol $200 \mu \mathrm{g}$ & 40 & 95.5 & & & \\
\hline \multicolumn{6}{|c|}{ Mean evening PEF (l/min) } \\
\hline Salmeterol $50 \mu \mathrm{g}$ & 40 & 268.0 & 4.6 & -4.0 to 13.3 & 0.288 \\
\hline Salmeterol $100 \mu \mathrm{g}$ & 38 & 268.0 & 7.5 & -1.4 to 16.4 & 0.097 \\
\hline Salbutamol $200 \mu \mathrm{g}$ & 40 & 261.6 & & & \\
\hline \multicolumn{6}{|c|}{ Predicted evening PEF (\%) } \\
\hline Salmeterol $50 \mu \mathrm{g}$ & 40 & 100.5 & 1.3 & -2.2 to 4.7 & 0.471 \\
\hline Salmeterol $100 \mu \mathrm{g}$ & 38 & 100.8 & 2.4 & -1.1 to 6.0 & 0.178 \\
\hline Salbutamol $200 \mu \mathrm{g}$ & 40 & 98.7 & & & \\
\hline \multicolumn{6}{|l|}{ Clinic visit $F E V_{1}($ (l) } \\
\hline Salmeterol $50 \mu \mathrm{g}$ & 41 & 1.75 & 0.03 & -0.04 to 0.1 & 0.439 \\
\hline Salmeterol $100 \mu \mathrm{g}$ & 40 & 1.70 & -0.02 & -0.09 to 0.05 & 0.585 \\
\hline Salbutamol $200 \mu \mathrm{g}$ & 41 & 1.72 & & & \\
\hline \multicolumn{6}{|l|}{ Clinic visit $P C_{20}$} \\
\hline Salmeterol $50 \mu \mathrm{g}$ & 14 & $0.47^{\star}$ & $1.54 \dagger$ & 0.65 to 3.70 & 0.306 \\
\hline Salmeterol $100 \mu \mathrm{g}$ & 15 & $0.37^{\star}$ & $1.23+$ & 0.55 to 2.78 & 0.598 \\
\hline Salbutamol $200 \mu \mathrm{g}$ & 16 & $0.30^{\star}$ & & & \\
\hline
\end{tabular}

$\mathrm{PEF}=$ peak expiratory flow $; \mathrm{FEV}_{1}=$ forced expiratory volume in one second; $\mathrm{PC}_{20}=$ concentration of histamine provoking a fall in $\mathrm{FEV}_{1}$ of $20 \%$.

*Adjusted geometric mean.

†Ratio of treatment:salbutamol.

\section{Results}

All statistical analyses were performed on the intent-to-treat population which consisted of 45 of the 52 subjects screened. A further five subjects withdrew from the study after randomisation. Three of the withdrawn subjects failed to return. These subjects were randomised to treatment sequences $\mathrm{ACB}, \mathrm{CAB}$, and $\mathrm{ACB}$ (where $\mathrm{A}=$ salmeterol $50 \mu \mathrm{g}, \mathrm{B}=$ salmeterol $100 \mu \mathrm{g}$, and C = salbutamol $200 \mu \mathrm{g}$ ) and withdrew during periods 1,2 , and 2 , respectively. One subject, randomised to sequence $\mathrm{ACB}$, withdrew due to non-compliance in the third period. The other withdrawal, randomised to sequence BCA, withdrew due to lack of efficacy in the first period. All subjects returned at least $80 \%$ of the prescribed study medication with the blisters pierced.

Thirty one $(69 \%)$ of the 45 subjects in the intent-to-treat population were boys with 24 $(77 \%)$ being less than 12 years of age. Of the 14 girls, $10(71 \%)$ were less than 12 years of age. The overall mean (SD) age of the subjects was 9 (2.8) years.

Eighty two percent of the subjects had a family history of asthma, $80 \%$ had a history of seasonal rhinitis, and $60 \%$ had a positive skin test to common allergens. All children had at least one exacerbation requiring a change in medication in the previous year, but only five had been admitted to hospital in that period. The main asthma triggers identified were exercise $(96 \%)$ and cold air $(91 \%)$.

The overall incidence of adverse events experienced during treatment was slightly higher with salbutamol $200 \mu \mathrm{g}(79 \%)$ than with salmeterol $50 \mu \mathrm{g}(64 \%)$ or $100 \mu \mathrm{g}(70 \%)$. However, for the most common adverse events (asthma, upper respiratory tract infection, cough, headache, and sore throat) there were no statistically significant differences between the treatment groups. Headache was the most commonly reported drug related adverse event in all three treatment groups. Nine patients in the intent-to-treat population experienced at least one serious adverse event during the run in period, study period, or follow up. Two subjects had serious adverse events that were considered to be possibly or probably related to study medication. However, on further follow up the investigator concluded that one these was unlikely to be related to study medication. No subjects died in the study and no patients were withdrawn because of an adverse event.

The primary efficacy analysis identified the two salmeterol treatments to be significantly more effective at increasing the mean morning PEF than salbutamol. For salmeterol $50 \mu \mathrm{g}$ versus salbutamol $200 \mu \mathrm{g}$ the estimated treatment difference was $9.6 \mathrm{l} / \mathrm{min}$ (95\% confidence interval (CI) 2.1 to 17.1 ), $p=0.013$. For salmeterol $100 \mu \mathrm{g}$ versus salbutamol $200 \mu \mathrm{g}$ the estimated treatment difference was $13.8 \mathrm{l} /$ $\min (95 \%$ CI 6.0 to 21.5$), p=0.001$. No significant difference was found between the two doses of salmeterol $(p=0.280$, table 2$)$.

Analysis of the percentage predicted mean morning PEF gave similarly significant results to the treatment differences. However, for the mean evening PEF and percentage predicted mean evening PEF, no significant treatment differences were identified. The clinic visit $\mathrm{FEV}_{1}$ also showed no differences between treatments. Only 14 subjects were tested for bronchial hyperreactivity $\left(\mathrm{PC}_{20}\right)$ on salmeterol $50 \mu \mathrm{g}, 15$ on salmeterol $100 \mu \mathrm{g}$, and 16 on salbutamol $200 \mu \mathrm{g}$ and no significant differences were found between the treatment groups.

The median percentage of days during which no rescue medication was required was greatly increased from baseline $(42 \%)$ for all three treatments: $61 \%$ for salmeterol $50 \mu \mathrm{g}, 72 \%$ for salmeterol $100 \mu \mathrm{g}$, and $65 \%$ for salbutamol $200 \mu \mathrm{g}$. However, Koch's method provided no evidence to suggest that any one treatment was more effective in increasing the percentage of days with no rescue medication. No significant differences were found between the treatment groups for the percentage of nights during which no rescue medication was required.

The median daytime symptom score improved from a baseline score of 1 to a score of 0 for all three treatments and the daytime symptom score remained at 0 for all treatments throughout the study. The percentage of symptom free days increased from baseline for all three treatments but there were no significant differences between them. The physician and child assessments of efficacy were the same for all study periods, with more than $50 \%$ rating the study medication as effective or very effective. These results provide no further evidence of any differences between treatments.

\section{Discussion}

This study has shown that, in addition to inhaled corticosteroids in doses of at least $400 \mu \mathrm{g} /$ day, the use of salmeterol $50 \mu \mathrm{g}$ bd and salmeterol $100 \mu \mathrm{g}$ bd provides significantly greater improvement in mean morning PEF (9.6 1/min and $13.8 \mathrm{l} / \mathrm{min}$, respectively) than 


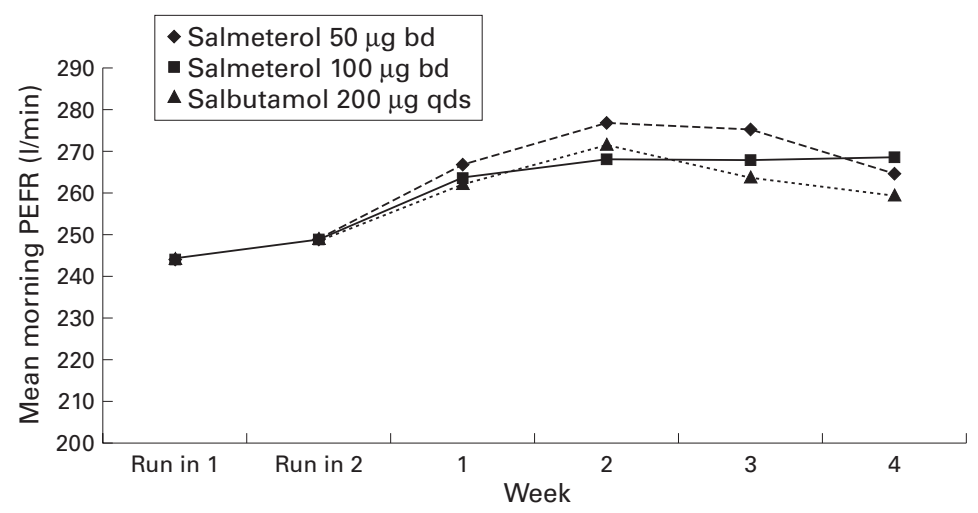

Figure 1 Mean morning peak expiratory flow rate (PEFR) over the four week treatment period, using the raw data. design would have been to provide as needed rather than regular salbutamol, ${ }^{5}$ but the children were already in effect using this strategy before joining the study and were still symptomatic, so we felt we had to offer an alternative strategy. The further alternative, that of doubling the dose of inhaled corticosteroids, would have been likely to require a longer study period and the comparison of these two strategies was not the aim of this study. We do not have any direct data on changes in airway inflammation. Clearly we could not have carried out bronchoscopy, lavage, and biopsy at the end of each treatment period in this group of children. At the time the study was carried out we did not have access to measurements of exhaled nitric oxide ${ }^{11}$ or induced sputum ${ }^{13}$ that would undoubtedly have supplemented our findings. However, even these techniques would have been difficult to apply in some of the younger children. We were able to measure bronchial hyperreactivity as a surrogate for airway inflammation ${ }^{14}{ }^{15}$ in about one third of the group, and reassuringly there was no change with treatment. However, this study cannot exclude the possibility of either short term or long term worsening of airway inflammation in any treatment arm.

Nonetheless, within the constraints of the study, the data provided no evidence of a significant advantage, in terms of the primary or secondary end points, of doubling the conventional dose of salmeterol. Previous dose response studies have compared salmeterol in doses up to $50 \mu \mathrm{g} \mathrm{bd}^{16-18}$ with conflicting results. Lenney et $a l^{16}$ compared $25 \mu \mathrm{g}$ with $50 \mu \mathrm{g}$ bd and showed that symptoms and morning and evening peak flow were higher with salmeterol $50 \mu \mathrm{g}$ bd. By contrast, de Benedictis $e t a l^{17}$ found that a single dose of $25 \mu \mathrm{g}$ salmeterol was equally as good as $50 \mu \mathrm{g}$ in preventing exercise induced bronchoconstriction. Weinstein et $a l^{18}$ reported a trend to greater bronchodilatation with $42 \mu \mathrm{g}$ than with $21 \mu \mathrm{g}$ salmeterol in 243 children but found no statistically different changes between the two doses. Primhak et $a l^{19}$ did show additional bronchoprotective effect against methacholine induced wheeze with an increase in a single salmeterol dose from 25 to $100 \mu \mathrm{g}$, but this was in younger children using a mask and spacer. It is difficult to compare airway deposition with this device and a dry powder device. Some of these apparent contradictions may be because the plateau of the dose response curves are at different doses for bronchodilatation and bronchoprotection. Our data imply that, at least for bronchodilatation, symptom score and use of rescue medication, the plateau has been reached by $50 \mu \mathrm{g}$ salmeterol twice daily in most individuals. This does not exclude the possibility that some individuals may benefit from a higher dose and, indeed, four children (10\%) did appear to show additional benefit at the higher dose.

The role of long acting $\beta_{2}$ agonists in paediatric asthma is still to be defined. They should only be used in children already taking inhaled corticosteroids, and not used as sole preventive treatment. ${ }^{20}{ }^{21}$ Several previous investigators 
have demonstrated benefit in children with asthma who had inadequate control on moderate doses of inhaled corticosteroids. ${ }^{1622} 23$ However, the role of long acting $\beta$ agonists in paediatric asthma was called into question by Verberne $e t a l^{6}$ who performed a randomised, double blind, parallel group study comparing beclomethasone $200 \mu \mathrm{g}$ bd plus placebo, beclomethasone $200 \mu \mathrm{g}$ bd plus salmeterol $50 \mu \mathrm{g}$ $\mathrm{bd}$, and beclomethasone $400 \mu \mathrm{g}$ bd in 177 children. They showed no difference in lung function, bronchial hyperreactivity, and asthma control in any of the three groups. This may be because they were studying children whose asthma was already well controlled (average rescue bronchodilator usage $<1$ dose/week). In our study, in which a much more symptomatic group of patients was studied, differences in the mean morning PEF were seen over the four week period with the different treatments, both doses of salmeterol giving significantly greater improvements in PEF than salbutamol. The symptomatic control of patients and use of rescue therapy improved over the four week period in all treatment groups, although the differences were not significant.

What then is the role of long acting $\beta_{2}$ agonists in paediatric asthma? They should never be used as monotherapy but, when added to inhaled corticosteroids, there is evidence for improved asthma control and better lung function with no deterioration in bronchial hyperreactivity, at least in the short term. For most children there will be no additional benefit in increasing the dose of salmeterol above $50 \mu \mathrm{g}$ bd, although a few children may benefit from a trial of $100 \mu \mathrm{g} \mathrm{bd}$. Although benefit can be obtained with regular short acting $\beta_{2}$ agonists, the improvement is less and the inconvenience of a four times daily regime is likely to make it less acceptable. The stage at which long acting $\beta_{2}$ agonists should be added rather than the dose of inhaled steroids increased remains to be agreed, at least in paediatric asthma.

CB was funded by a grant from GlaxoWellcome for the duration of this study.

1 British Thoracic Society, National Asthma Campaign, Royal College of Physicians of London, et al. The British guidelines on asthma management: 1995 review and position statement. Thorax 1997;52(Suppl 1):S1-21.
2 Greening AP, Ind PW, Northfield M, et al. Added salmeterol versus higher-dose corticosteroid in asthma patients with versus higher-dose corticosteroid in asthma patients with
symptoms on existing inhaled corticosteroids. Lancet 1994; symptoms on

3 Woolcock A, Lundback B, Ringdal N, et al. Comparison of addition of salmeterol to inhaled steroids with doubling of the dose of inhaled steroids. Am $\mathcal{F}$ Respir Crit Care Med 1996;153:1481-8.

4 Pauwels RA, Lofdahl CG, Postma DS, et al. Effect of inhaled formoterol and budesonide on exacerbations of asthma. $N$ Engl F Med 1997;337:1405-11.

5 Russell G, Williams DAJ, Weller P, et al. Salmeterol xinafoate in children on high dose inhaled steroids. Ann Allergy Asthma Immunol 1995;75:423-8.

6 Verberne AAPH, Frost C, Duiverman EJ, et al. Addition of salmeterol versus doubling the dose of beclomethasone in children with asthma. Am $\mathcal{F}$ Respir Crit Care Med 1998;158: 213-9.

7 Koch GG. The use of non-parametric methods in the statistical analysis of two-periods change-over design. Biometrics 1972;28:577-84.

8 Cornell RG. Evaluation of bioavailability using nonparametric statistics. In: Albert KS, ed. Drug absorption and disposition: statistical considerations. American Pharmaceutical Association, 1980.

9 Verberne AAPH, Hop WCJ, Creyghton FBM, et al. Airway responsiveness after a single dose of salmeterol and during four months of treatment in children with asthma. $\mathcal{f}$ Allergy Clin Immunol 1996;97:938-46.

10 Nelson JA, Strauss L, Skowronski M, et al. Effect of long-term salmeterol treatment on exercise-induced asthma. N Engl F Med 1998;339:141-6.

11 Byrnes CA, Dinarevic S, Shinebourne EA, et al. Exhaled nitric oxide measurements in normal and asthmatic children. Pediatr Pulmonol 1997;24:312-8

12 Nelson BV, Sears S, Woods J, et al. Expired nitric oxide as a marker for childhood asthma. F Pediatr 1997;130:423-7.

13 Cai Y, Carty K, Gibson PG. Persistence of sputum eosinophilia in children with controlled asthma when compared with healthy children. Eur Respir f 1998;11:848-53.

14 Sont JK, Willems LNA, Bel EH, et al. Clinical control and histopathological outcome of asthma when using airway hyperresponsiveness as an additional guide to long-term treatment. Am f Respir Crit Care Med 1999;159:1043-51.

15 Haley KJ, Drazen JM. Inflammation and airway function in asthma: what you see is not necessarily what you get. $A m \mathcal{F}$ asthma: what you see is not necessarily
Respir Crit Care Med 1998;157:1-3.

16 Lenney W, Pedersen S, Boner AL, et al. Efficacy and safety of salmeterol in childhood asthma. Eur f Pediatr 1995;154: 983-90

17 de Benedictis FM, Tuteri G, Pazzelli P, et al. Salmeterol in exercise-induced bronchoconstriction in asthmatic children: comparison of two doses. Eur Respir $\mathcal{F}$ 1996;9: 2099-103.

18 Weinstein S, Chervinsky P, Pollard SJ, et al. A one-week dose-ranging study of inhaled salmeterol in children with asthma. $\mathcal{F}$ Asthma 1997;34:42-52.

19 Primhak RA, Smith CM, Yong SC, et al. The bronchoprotective effect of inhaled salmeterol in preschool children: a dose-ranging study. Eur Respir f 1999;13:78-81.

20 Verberne AAPH, Frost C, Roorda RJ, et al. One year treatment with salmeterol compared with beclomethasone in children with asthma. Am f Respir Crit Care Med 1997;156: 688-95.

21 Simons FER for the Canadian Beclomethasone Dipropionate and Salmeterol Xinafoate Study Group. A comparison of beclamethasone, salmeterol, and placebo in children with asthma. N Engl f Med 1997;337:1659-65.

22 Meijer GG, Postma DS, Mulder PGH, et al. Long-term effects of salmeterol in asthmatic children treated with inhaled corticosteroids. Am $\mathcal{f}$ Respir Crit Care Med 1995;152:1887-92.

23 Mahajan P, Stahl E, Arledge T. Quality of life in pediatric asthma patients treated with salmeterol and impact on the daily actiivities of their patients. Pediatr Asthma Allergy Immunol 1998;12:21-8. 